\title{
PERIODO A PRUEBA Y CAPACITACIÓN INICIAL. NUEVAS MODALIDADES DE CONTRATACIÓN LABORAL EN MÉXICO
}

TEST AND INITIAL TRAINING PERIOD. NEW MODALITIES OF LABOR RECRUITMENT IN MEXICO

\author{
Verónica Alejandra Curiel Sandoval ${ }^{1}$ \\ Juan Pablo Sánchez Tejeda²
}

\section{Resumen}

El derecho laboral es producto de la lucha de miles de personas que perdieron su vida reclamando mejores condiciones de trabajo, por este motivo, hasta hace algunos años, era considerado como uno de los avances jurídicos más importantes para la clase trabajadora; sin embargo, el neoliberalismo ha ocasionado que la relación trabajador-patrón sufra una transformación atroz que lesiona los derechos individuales y colectivos de toda la clase trabajadora, es por ello que la flexibilización laboral, se ha convertido en una herramienta primordial e indispensable a nivel mundial. Un ejemplo de lo mencionado es la reforma laboral mexicana de 2012, cuya aprobación le dio legalidad tanto a la contratación con periodo a prueba como a la contratación de capacitación inicial.

Palabras clave: Relación Individual de Trabajo; Contrato Individual de Trabajo; Contrato de Capacitación Inicial; Contratación a Prueba; Ley Federal de Trabajo (México)

\begin{abstract}
Labor law is the product of the struggle of thousands of people who lost their lives demanding better working conditions. For this reason, until some years ago it was considered one of the most important legal advances for the working class; However, neoliberalism has caused the worker-employer relationship to undergo an atrocious transformation that damages the individual and collective rights of the entire working class, which is why labor flexibilization has become a primordial and indispensable tool worldwide. An example of this is the Mexican labor reform of 2012, whose approval gave legality to both hiring with probation period and the hiring of initial training.
\end{abstract}

Keywords: Individual Work Relationship; Individual Work Contract; Initial Training Contract; Hiring on Probation; Law Federal of Work (Mexico)

\footnotetext{
1 Profesora de la Universidad Autónoma Metropolitana, Ciudad de México. E-mail: vacs@correo.azc.uam.mx

${ }^{2}$ Profesor de la Universidad Autónoma Metropolitana, Ciudad de México. E-mail: ptejeda93@yahoo.com
} 


\section{INTRODUCCIÓN}

Desde hace algunos años, los patrones han comenzado a utilizar diversas artimañas para aumentar su competitividad y obtener mayor plusvalía de los trabajadores. Las estrategias van encaminadas a disminuir al máximo los derechos laborales que durante años se han conseguido, incluyendo la seguridad social del trabajador; por lo anterior, ha resultado fundamental para el sector patronal flexibilizar los contratos laborales, afectando considerablemente la estabilidad en el empleo.

El derecho del trabajo atraviesa por una época con diversas complejidades que impiden que se tenga claridad respecto a las múltiples preguntas que surgen en relación a la lucha de clases o a la contraposición que existe en los intereses de los factores de poder presentes en la sociedad, lo anterior dificulta que sea posible explicar o justificar su realidad actual. En este sentido podemos afirmar que:
El régimen económico vigente se sustenta en las relaciones de producción que se generan en su base. Es en ésta en donde encontramos sus dos polos: el propietario de los medios de producción y el poseedor de la fuerza de trabajo (...)
En el caso de México, el precepto jurídico encargado hoy en día de entablar esas relaciones, presenta dos opciones: el contrato de trabajo y la relación de trabajo $(. . .)^{3}$

La diversidad en los planteamientos de los requerimientos del sector capitalista así como su necesidad por obtener mayor plusvalía, exigen que exista insuficiente protección jurídica para los trabajadores, fragmentando prácticamente todos los argumentos legales que invitan a salvaguardar a la parte más indefensa del vínculo laboral; es así que, el tema del contrato en la relación de trabajo, trae a la realidad jurídica cambios profundos y sustanciales en los elementos que lo componen,

Desde la entrada en vigor de la reforma a la Ley Federal del Trabajo (LFT) aprobada en noviembre de 2012 en México, distintos artículos adicionados o modificados han contribuido significativamente a la precarización de las condiciones con las que se puede contratar a los trabajadores en nuestro país. Lo anterior es un grave y lamentable retroceso histórico para la sociedad mexicana en relación de la protección de la contratación por tiempo indeterminado, ya que, aunque la legislación contenga ciertas normas jurídicas que limitan cualquier contratación diferente a la mencionada, en la cotidianidad, se han utilizado diversos

\footnotetext{
${ }^{3}$ Octavio Lóyzaga de la Cueva, El derecho del trabajo. Un análisis crítico (México: Universidad Autónoma Metropolitana, 2015), 51.
} 
mecanismos legales para facilitar su implementación, favoreciendo en todo momento al sector patronal.

Algunas de las modificaciones importantes y especiales que surgieron como producto de la reforma laboral de 2012 son dos modalidades de contratación laboral que se pueden aplicar obedeciendo a ciertas restricciones señaladas en la LFT: el periodo de capacitación inicial y el periodo de prueba; mismos que aparentemente permitirían al patrón disfrutar de un tiempo breve para conocer la aptitud, competencia y dedicación de los trabajadores en el empleo; empero, las modalidades mencionadas, han dejado de ser modalidades dentro de un contrato laboral y, se han convertido en tipos de contratos de trabajo que se utilizan de manera independiente, lo anterior como consecuencia de las estrategias patronales que buscan mayor flexibilización en los vínculos laborales.

\section{RELACIÓN Y CONTRATO INDIVIDUAL DE TRABAJO}

Las nuevas tendencias que persigue la legislación aplicable al derecho del trabajo, van dejando de lado el respeto a la idea de un derecho protector de las relaciones laborales y, en consecuencia, el trabajador comienza a ser víctima de severos abusos patronales. De lo señalado se desprende que en el ámbito contractual se declare un estado de emergencia debido al establecimiento de modalidades de contratación que comienzan a ser implementados como tipos de contratos laborales, lo anterior debido a un mal uso de la legislación aplicable, algunos ejemplos que comienzan a ser comunes a nivel internacional son los: ellos el artículo 20 de la LFT textualmente dice que:

(...) contratos de aprendizaje, por tiempo determinado, a tiempo parcial, intermitente o temporal, el desarrollo del teletrabajo; asimismo, nacen nuevos contratos, los de formación profesional o de inserción profesional, por ejemplo, el contrato de empleo-solidaridad, contrato de aprendizaje, contrato de estancia profesional, contrato iniciativa-empleo, contrato a prueba, contrato de reinserción profesional, etcétera. ${ }^{4}$

Es necesario mencionar que, en el caso mexicano, no es lo mismo tratar la temática relacionada con la relación individual de trabajo que la ligada al contrato individual de trabajo, aunque están íntimamente vinculados; sin embargo, no deben confundirse entre sí, por lo que resulta equívoco referirse a ellos como sinónimos. Para identificar a cada uno de ellos el artículo 20 de la LFT textualmente dice que:

\footnotetext{
4 Alfredo Sánchez-Castañeda, Las transformaciones del derecho del trabajo (México: Universidad Nacional Autónoma de México, 2006), 28.
} 
Se entiende por relación de trabajo, cualquiera que sea el acto que le dé origen, la prestación de un trabajo personal subordinado a una persona, mediante el pago de un salario.

Contrato individual de trabajo, cualquiera que sea su forma o denominación, es aquel por virtud del cual una persona se obliga a prestar a otra un trabajo personal subordinado, mediante el pago de un salario.

Por lo tanto una relación de trabajo surge cuando entre el patrón y el trabajador se inicia un vínculo laboral en donde mediante la subordinación el trabajador personalmente deberá proporcionar un servicio o realizar alguna actividad para el patrón, quien a cambio, le otorgará un salario como retribución, mientras que el contrato laboral surge cuando se acuerden las condiciones en las que se cubrirá el trabajo o servicio, ya que en el contrato existe un acuerdo de voluntades por medio del que se establecen derechos u obligaciones.

Con respecto a lo señalado se puede aseverar que:

La existencia de una relación de trabajo depende, en consecuencia, no de lo que las partes hubieren pactado, sino de la situación real en que el trabajador se encuentre colocado en la prestación del servicio; y es porque (...) la aplicación del derecho del trabajo depende cada vez menos de una relación jurídica subjetiva, cuanto de una situación objetiva, cuya existencia es independiente del acto que condiciona su nacimiento. ${ }^{5}$

Por otra parte cabe mencionar que el término salario queda definido en el artículo 82 de la LFT como: "la retribución que debe pagar el patrón al trabajador por su trabajo"; mientras que el artículo 8 primer párrafo de la LFT concibe al trabajador como "la persona física que presta a otra, física o moral, un trabajo personal subordinado", como se señala, el trabajador forzosamente deberá ser una persona física pero que además deberá prestar los servicios o desempeñar el trabajo subordinado de manera personal y directa, nunca por conducto de un tercero . El concepto de trabajo se aborda en el artículo 8 segundo párrafo y es: "toda actividad humana, intelectual o material, independientemente del grado de preparación técnica requerido por cada profesión u oficio", por último la figura de patrón se concibe mediante el artículo 10 como la: "persona física o moral que utiliza los servicios de uno o varios trabajadores", por lo que podemos afirmar que a diferencia del trabajador, el patrón podrá ser una persona física o una empresa (persona moral) sin que esto sea una limitante para dar origen a la relación laboral.

De lo comentado se desprende que las partes que forzosamente deben concurrir para poder originar una relación laboral y un contrato laboral son el trabajador y el patrón, mediante un vínculo en el cual el trabajador quedará subordinado al patrón. Con respecto a la definición

\footnotetext{
${ }^{5}$ Mario de la Cueva, El nuevo derecho mexicano del trabajo, Tomo I (México: Porrúa, 2011), 458.
} 
del concepto de subordinación la Suprema Corte de Justicia de la Nación (SCJN) resolvió mediante la siguiente Tesis Jurisprudencial IV.20.J/1, de mayo de 1995, cuyo rubro es: "RELACIÓN LABORAL. LA SUBORDINACIÓN ES EL ELEMENTO DISTINTIVO DE LA" lo que se indica a continuación:

El artículo 20 de la Ley Federal del Trabajo, establece que por relación de trabajo debe entenderse la prestación de un trabajo personal subordinado a una persona mediante el pago de un salario. Así pues, la relación laboral tiene como elemento distintivo la subordinación jurídica entre patrón y trabajador, en virtud de la cual el primero se encuentra en todo momento en posibilidad de disponer del trabajo del segundo, quien a su vez tiene la obligación correlativa de acatar al patrón.

De lo estipulado por el artículo 20 ya comentado, se desprende también que en una relación o en un contrato laboral, no importará la forma o denominación que les dé origen, tampoco es necesario que forzosamente exista un contrato por escrito para que la relación de trabajo sea válida, sino que es suficiente con que se cumplan los elementos anteriormente expuestos: el trabajo personal, la subordinación y el salario, para afirmar que existe una relación de tipo laboral entre las partes.

La subordinación se entiende como la propia autoridad que tiene el patrón sobre su trabajador, aunque es fundamental decir que únicamente se podrá tener a disposición a los trabajadores durante la jornada laboral o la extensión de la misma; lo anteriormente señalado se debe a que, el trabajador vende su fuerza de trabajo, pero no vende su persona, por lo que resultaría equívoco que un patrón quiera seguir teniendo subordinado al trabajador en los periodos de reposo ajenos a la jornada laboral:

La subordinación es la base para que se dé la relación laboral, ya que entraña la facultad de imperio que tiene el patrón, así como la prerrogativa que tiene de obediencia en la relación de trabajo.

En la prestación del servicio, el trabajador debe sujetarse a las órdenes que establezca el patrón, y por lo tanto, no podrá negarse a cumplirlas, ya que la condición de la relación de trabajo establece como obligación principal la obediencia que le debe al patrón $(. . .)^{6}$

La flexibilidad a la que se encuentra expuesta actualmente la LFT, se ha convertido en un verdadero peligro, lo anterior debido a que los patrones la utilizan para atentar al principio de estabilidad en el empleo.

Es menester mencionar que el artículo 40 de la LFT contempla que: "Los trabajadores en ningún caso estarán obligados a prestar sus servicios por más de un año", con lo que cualquier tipo de contrato que se extienda por más del periodo señalado, otorgará al trabajador

\footnotetext{
${ }^{6}$ Ricardo de la Luz Félix Tapia, Relaciones Laborales. Legislación, formularios y jurisprudencia (México: Flores Editor y Distribuidor, 2008), 13.
} 
la facultad discrecional de decidir respecto a si decide o no mantener vigente el vínculo obreropatronal. Lo que demuestra el artículo en comentario, es que el trabajador tiene la libertad de prestar sus servicios según su voluntad, lo que obedece también a lo indicado en el artículo 5 de la Constitución Política de los Estados Unidos Mexicanos que indica: "Nadie podrá ser obligado a prestar trabajos personales (...) sin su pleno consentimiento". Desde este panorama, así como el trabajador de manera voluntaria aceptó el trabajo, también decidirá si quiere o no laborar por más de un año, este precepto legal, procura proteger al trabajador de cualquier arbitrariedad que el patrón desee entablar en su contra, abusando del tiempo establecido.

En la relación de trabajo no se considera la forma, denominación o el acto que le da origen, lo importante es que se presta un trabajo personal subordinado a un patrón que tiene como retribución el salario. Por otro lado, el contrato individual de trabajo se define mediante el artículo 20 de la LFT como un convenio o un acuerdo mediante el cual un trabajador se obliga a prestar un trabajo personal subordinado a un patrón a cambio de un salario. De tal manera que la contratación laboral puede ser verbal, escrita o tácita. De lo comentado se desprende que las obligaciones principales son: prestar el servicio de manera personal, no olvidar la subordinación y, tampoco olvidar el salario o retribución. Para complementar lo señalado, el artículo 21 de la LFT trae a la realidad la presunción tanto de la existencia del contrato como de la relación laboral entre el trabajador y el patrón, en este sentido, la relevancia conlleva al análisis de los efectos legales que se producen como consecuencia.

Actualmente tanto en la situación nacional como en la internacional se han presentado múltiples cambios que repercuten en las relaciones obrero-patronales, que nos llevan a afirmar que:

(...) la crisis económica mundial y la transnacionalización de la economía repercutieron en el ámbito de las relaciones laborales (...) Las nuevas relaciones de trabajo se caracterizan por la inestabilidad en el empleo y la precarización (...) de un denominado sector no estructurado que escapa a cualquier reglamentación (...) por la posibilidad de modificar el tiempo de trabajo a fin de adaptarlo a las condiciones de producción o las necesidades de la empresa. ${ }^{7}$

De lo expuesto se desprende que, independientemente de los diversos tipos de contratación que se encuentran vigentes, existe una necesidad constante por parte de los patrones para buscar alternativas que les permitan flexibilizar las relaciones laborales y, así, volverse más competitivos en el mercado nacional o internacional.

\footnotetext{
${ }^{7}$ Sánchez-Castañeda, Las transformaciones, 7.
} 
El vínculo que nace de la relación laboral que une al patrón y al trabajador, lleva indirectamente la aceptación o voluntad de un acuerdo entre las partes, no importando si la voluntad es tácita o expresa. Debemos recordar que un contrato es aquel que se utiliza para crear o transmitir derechos y obligaciones $y$, aunque por costumbre los contratos se pactan por escrito, en el caso del derecho mexicano del trabajo, no existe diferencia alguna entre los derechos, obligaciones, libertades y consecuencias que surgen mediante los contratos laborales verbales y los escritos, pues lo importante no es la forma o denominación, sino la acreditación de la existencia de la relación de trabajo.

Cabe señalar que para las nuevas modalidades de contratación que se abordan en la presente investigación, los legisladores intentaron colocar en el año 2012 ciertas restricciones (mismas que serán estudiadas más adelante) que servirían para evitar cualquier tipo de contravención que quisiera imponerse al ordenamiento jurídico aprobado; sin embargo, el sector patronal ha encontrado la forma de alterar la legalidad y hacer creer al trabajador que se cumple con lo dispuesto en la LFT, con lo que se aparenta una contratación legal cuando no lo es.

\section{EL CONTRATO LABORAL ESCRITO}

Recibe el nombre de contrato al acuerdo establecido entre 2 o más personas (que tengan capacidad legal) en donde pueden producirse o transferirse derechos y obligaciones. Sus elementos son el consentimiento (que no debe tener vicios) y el objeto materia del contrato, señalándose que éste debe ser lícito; sin embargo, debemos considerar fundamental comprender que "un nuevo enfoque (...) se abre camino en nuestro tiempo, originado más por los problemas que se viven que por afán de modificar las instituciones o los conceptos tradicionales". 8

Existen presupuestos jurídicos relacionados con el contrato laboral, mismos que no se pueden olvidar, como son: capacidad, idoneidad y la legitimidad. Con respecto a lo señalado se puede aseverar que:

Según la doctrina jurídica, los presupuestos son elementos extrínsecos del contrato, por lo que deben existir antes de la celebración del contrato y se necesitan para convalidar el acto jurídico. Los presupuestos de validez que la doctrina exige son tres: uno en referencia al sujeto del contrato, la capacidad; otro en referencia al objeto del contrato, la

\footnotetext{
${ }^{8}$ Santiago Barajas Montes de Oca, Los contratos especiales de trabajo (México: Universidad Nacional Autónoma de México, 1992), 14.
} 
idoneidad, y el último referido a la situación del sujeto respecto del objeto, la legitimación. ${ }^{9}$

La capacidad. Jurídicamente se relaciona de manera directa con los sujetos que celebran el contrato laboral. Para tener capacidad jurídica físicamente se deben tener 15 años de edad además de contar con buena salud mental. En el caso de las personas morales, se debe considerar que los representantes serán los que cuenten con la capacidad adecuada para celebrar el contrato.

Idoneidad. Va relacionada con el objeto del contrato, que contempla cualquier aspecto relacionado con la posibilidad de realizarla; para lo cual, se deben considerar tanto las posibilidades del ámbito legal, vinculadas a la licitud de la prestación de los servicios o a la licitud del objeto y, por otra parte, tenemos las del ámbito físico, que se reflejan en las posibilidades de las condiciones humanas de las personas que intervienen en el contrato y con la esencia natural de las cosas.

Legitimidad. La palabra legitimidad proviene del término "legitimare", cuyo significado es "cumplir la ley". De tal manera que, la legitimidad va relacionada con las posibilidades que se tienen para la celebración del contrato, en donde se incluye la capacidad y la legalidad, de tal manera que, para que el contrato sea legitimo, se debe cumplir con lo dispuesto en la legislación que corresponda.

En materia laboral, al momento en que surge una relación de trabajo, las partes (el patrón y el trabajador) automáticamente adquieren los derechos y las obligaciones contenidas en la LFT. En este contexto y atendiendo a lo establecido por el artículo 20 (ya comentado) no importará el acto que dé origen a la relación laboral, por lo cual se entiende que la relación obrero-patronal puede surgir mediante un acuerdo verbal pero también puede originarse de un acuerdo que quede plasmado de manera escrita. Al respecto cabe señalar que los acuerdos verbal o escrito, surten los mismos efectos legales; es decir, el hecho de que la relación laboral emane de un acuerdo verbal no restará derechos u obligaciones al patrón o al trabajador, aunque en muchas ocasiones exista la idea de que así es. Al respecto, es menester señalar como la Cuarta Sala de la SCJN resolvió en la sexta época, a través de la Tesis Aislada con número de registro 273543 y de rubro: CONTRATO VERBAL DE TRABAJO. ALCANCE Y EFECTOS DEL ARTíCULO 31 DE LA LEY FEDERAL DEL TRABAJO, lo que textualmente se indica a continuación:

Si bien es cierto que conforme al artículo 31 de la Ley Federal del Trabajo "La falta de contrato escrito, cuando en esta forma lo prevenga la ley, o de alguno de los requisitos que para el mismo señala el artículo 24, no privará al trabajador de los derechos que esta ley o el contrato le concedan, pues se imputará al patrón la falta de esa formalidad ...", también lo es que los términos que establece esa disposición laboral en beneficio de los trabajadores, no pueden tener el alcance y efectos al extremo de que se tengan por ciertas las peticiones que hace un trabajador en su demanda, por el solo hecho de que los enunciare en su

\footnotetext{
${ }_{9}^{9}$ Miguel Bermúdez Cisneros, Derecho del trabajo (México: Oxford, 2012), 101.
} 
demanda laboral, ya que las cuestiones que se alegan pactadas en un contrato, deben ser expresamente probadas en autos, pese a que no se hubiere otorgado por escrito el correspondiente contrato laboral, por causas imputables al patrón.

Amparo directo 8147/62. Guillermo Corres Innes. 25 de febrero de 1965. Unanimidad de cinco votos. Ponente: Manuel Yáñez Ruiz.

Al contrario de lo comentado en líneas anteriores, es conveniente señalar que el artículo 24 de la LFT dispone que: "Las condiciones de trabajo deben hacerse constar por escrito... Se harán dos ejemplares... de los cuales quedará uno en poder de cada parte", es decir al trabajador se debe entregar una copia del escrito de las condiciones de trabajo, mientras que el patrón deberá quedarse con otra copia; pese a lo mencionado, en múltiples ocasiones, los trabajadores afirman no haber recibido la copia de su contrato. El artículo 25 complementa lo establecido por el 24, además de que su importancia radica en el hecho de que en él se señalan las condiciones esenciales que deberá cubrir o contener el escrito referido con antelación, algunas de las que se enlistan a continuación:

1. Denominación del contrato, indicando el tipo de relación laboral a la que se hará referencia en el escrito.

2. Nombre completo de cada una de las partes, aunado a la calidad o denominación que adquieren con el contrato.

3. Declaraciones o datos generales de cada parte o sujeto (bajo protesta de decir verdad): Edad, nacionalidad, sexo, estado civil, domicilios.

4. Fundamento legal del contrato.

5. Cláusulas en donde se especifiquen tanto los derechos y obligaciones de las partes. A continuación, mencionaremos algunos:

a. Categoría o puesto que tendrá el trabajador.

b. Lugar de trabajo (domicilio completo y exacto en donde deberá prestar sus servicios el trabajador).

c. Fecha de inicio y termino de labores. (Si vencido el término el patrón continúa con la relación, entonces se entenderá que a pesar de la firma de este contrato la relación pasará a ser de tiempo indeterminado).

d. Actividades completas que desempeñará el trabajador.

e. Jornada laboral, horario de trabajo y días de descanso; asimismo, deberá aclararse en qué casos pueden variar y cuáles serán los beneficios para el trabajador. Además, se debe abordar también lo relativo al aguinaldo y a las vacaciones.

f. Salario y sus descuentos. 
g. Prestaciones y disposiciones con respecto a la Seguridad Social.

h. Disposiciones relativas a la participación de utilidades.

i. Ascensos y escalafón del trabajador.

j. Materiales, herramientas, instrumentos, útiles o equipo de trabajo que se le proporcionará al trabajador.

k. Capacitación y adiestramiento laboral.

I. Seguridad, higiene y medio ambiente para el trabajo.

m. Indicar si existe un Contrato Colectivo de Trabajo y un Reglamento Interior de Trabajo.

6. Fecha de la celebración del Contrato.

7. Firma de cada una de las partes.

8. Firma de 2 testigos (aunque este elemento no es obligatorio).

Resulta fundamental mencionar que con base en el artículo 35 de la LFT existen diversos tipos de relación laboral: por obra determinada, por tiempo determinado, por temporada y por tiempo indeterminado, además en algunos casos la relación podría quedar sujeta a prueba o a capacitación inicial, es aquí en donde quedan legalizadas las modalidades que se analizan en la presente investigación. Cabe mencionar que la ley mediante los artículos 36 y 37 exige que se atienda a la propia naturaleza de la relación para los casos en que vaya a señalarse que será por tiempo u obra determinada; mientras que el primer párrafo del artículo 39-A señala que en las relaciones laborales de carácter indeterminado o que para su tiempo de realización se requieran más de ciento ochenta días (seis meses), se podrá establecer un periodo a prueba, que no podrá exceder de treinta días. En lo que corresponde a la contratación para capacitación inicial, el artículo 39 B la identifica como "aquélla por virtud de la cual un trabajador se obliga a prestar sus servicios subordinados, bajo la dirección y mando del patrón, con el fin de que adquiera los conocimientos o habilidades necesarios", por lo que resulta claro que la capacitación inicial se permite en cualquier tipo de relación laboral.

En todos los casos en que no se estipule de manera expresa el tipo de vínculo laboral, se entenderá que son por tiempo indeterminado; en consecuencia, en cualquiera de las relaciones laborales que no sean de base, será indispensable que se manifiesten por escrito; por lo cual, los contratos de capacitación inicial o de periodo a prueba deben obedecer a lo comentado.

Para reforzar legalmente lo comentado, el artículo 39-C manifiesta que: "La relación de trabajo con periodo a prueba o de capacitación inicial, se hará constar por escrito garantizando la seguridad social del trabajador; en caso contrario se entenderá que es por tiempo indeterminado, y se garantizarán los derechos de seguridad social del trabajador", aquí radica 
una de las limitantes legales principales, pues el hecho de que obre por escrita la justificación de la necesidad de la modalidad, evita que el patrón haga una simulación jurídica que afecte o menoscabe los derechos del trabajador.

Con lo establecido a través del artículo en comentario, podemos reiterar que para los casos de que la relación laboral inicie con la contratación del trabajador con un periodo de prueba o de capacitación inicial, se debe tener en consideración que si no se específica por escrito el tipo de relación laboral de que se trata; es decir, si existe una falta de estipulación expresa, la duración del vínculo laboral forzosamente se convertirá en tiempo indeterminado, por lo que para evitar problemáticas legales, el patrón deberá buscar su protección estipulando las condiciones de trabajo mediante un contrato escrito. Es sumamente importante mencionar que la fuerza de trabajo que sea contratada a prueba o por capacitación inicial (o cualquier periodo diferente al indeterminado), debe recibir toda la protección legal, así como a las prestaciones, seguridad social y cualquier otra que se abarque en la LFT para el tiempo que se mantenga activa la relación obrero-patronal.

Es importante mencionar que cuando concluya el tiempo establecido para la contratación a prueba o de capacitación inicial y el patrón no dé por terminado el vínculo, automáticamente se convertirá en una relación por tiempo indeterminado, lo anterior se manifiesta con base al artículo 39-E. La LFT con el artículo 39-D es muy clara al afirmar que, al cumplirse los lapsos señalados para duración máxima de las contrataciones en comentario, los tiempos serán improrrogables, aunado al hecho de que:

Dentro de una empresa o establecimiento, no podrán aplicarse al mismo trabajador en forma simultánea o sucesiva períodos de prueba o de capacitación inicial, ni en más de una ocasión, ni tratándose de puestos de trabajo distintos, o de ascensos, aun cuando concluida la relación de trabajo surja otra con el mismo patrón, a efecto de garantizar los derechos de la seguridad social del trabajador.

Por lo que cualquier práctica patronal en donde se rompa con lo mencionado en el párrafo anterior, carecería de legalidad y fundamentación jurídica. Es decir, únicamente puede aplicarse una contratación de éste tipo a cualquier trabajador y sólo por el tiempo máximo que se indica en la ley.

Si terminado el plazo del contrato a prueba o el de capacitación inicial el patrón contrata definitivamente al trabajador, la antigüedad deberá ser contada desde el día en que inició la prestación del servicio y no sólo a partir de la respuesta afirmativa del patrón para contratar indeterminadamente al trabajador. 
Existen tres momentos en particular para identificar la protección del contrato sobre el trabajo: al acordar el inicio de labores, la protección durante la relación de trabajo y el auxilio al momento de finalizar el vínculo laboral.

Como podemos analizar, en el derecho del trabajo "el consentimiento se manifiesta en tres formas: verbal o por escrito, siempre que acepten mutuamente las condiciones, y expreso o tácito cuando las partes realicen actos que lo presuponen". ${ }^{10}$

\section{EL CONTRATO DE CAPACITACIÓN INICIAL}

La contratación de trabajadores por relación laboral de capacitación inicial será establecida, como su nombre claramente lo indica, para que los trabajadores reciban la instrucción correspondiente con el puesto de trabajo en el cual van a prestar sus servicios. La palabra capacitación significa "preparar al trabajador para el desarrollo y desempeño de un trabajo". ${ }^{11}$

Los trabajadores son contratados bajo esta modalidad porque no cuentan con la experiencia necesaria para desempeñar las funciones propias con la categoría o puesto de trabajo vacante; por ello, es necesario que adquieran previamente los conocimientos que no poseen. En tal sentido, el artículo 39-B dispone lo siguiente:

La vigencia de la relación de trabajo a que se refiere el párrafo anterior, tendrá una duración máxima de tres meses o en su caso, hasta de seis meses sólo cuando se trate de trabajadores para puestos de dirección, gerenciales y demás personas que ejerzan funciones de dirección o administración en la empresa o establecimiento de carácter general o para desempeñar labores que requieran conocimientos profesionales especializados. Durante ese tiempo el trabajador disfrutará del salario, la garantía de la seguridad social y de las prestaciones de la categoría o puesto que desempeñe. Al término de la capacitación inicial, de no acreditar competencia el trabajador, a juicio del patrón, tomando en cuenta la opinión de la Comisión Mixta de Productividad, Capacitación y Adiestramiento en los términos de esta Ley, así como a la naturaleza de la categoría o puesto, se dará por terminada la relación de trabajo, sin responsabilidad para el patrón.

Considerando lo establecido por la LFT, aunque el trabajador va a recibir por parte del patrón la instrucción correspondiente al puesto de trabajo en el que se le va a contratar, ello no exime al patrón de otorgar el salario y cumplir con las obligaciones patronales establecidas en la LFT.

\footnotetext{
${ }^{10}$ Alena Garrido Ramón, Derecho individual del trabajo (México: Oxford, 2015), 52.

11 Juan Hernández Herrera y Carlos Antonio Juárez Suárez, Derecho laboral y la administración de recursos humanos (México: Grupo editorial patria, 2015), 108.
} 
Como se indica, la duración máxima de una relación laboral bajo esta figura será de 3 meses, pero se podrá extender a 6 meses cuando el trabajador necesite adquirir conocimientos ya sea técnicos, mayormente profesionales o especializados, o también, se podrá extender cuando deba desempeñar actividades en donde la tarea fundamental será la de llevar la dirección o administración de la empresa, establecimiento o fuente de trabajo. En caso de que termine el tiempo señalado en el contrato y el patrón opine que el trabajador no es capaz de desempeñar el trabajo, podrá terminar la relación sin responsabilidad alguna, sólo que para dar legalidad a su decisión deberá tomar en consideración lo que pueda opinar la Comisión Mixta de Capacitación, Adiestramiento y Productividad (CMCAP); sin embargo, dicha Comisión únicamente se requiere en las fuentes laborales que tengan más de 50 trabajadores, por lo que en cualquier fuente de trabajo que tenga menos del número de trabajadores indicado, se dejará a voluntad discrecional del patrón la toma de decisión. Como consecuencia de lo comentado anteriormente y de lo que se estipula en el artículo 39-B podemos preguntarnos lo siguiente: ¿Quiénes pueden conformar la CMCAP? ¿Cómo deberán quedar constituidas estas comisiones para la protección del trabajador? Pues bien, con la reforma realizada a la LFT en noviembre de 2012, la Secretaría del Trabajo y Previsión Social (STPS) publicó el día 30 de mayo de 2013 en el Diario Oficial de la Federación (DOF) el denominado "Acuerdo por el que se dan a conocer los criterios administrativos, requisitos y formatos para realizar los trámites y solicitar los servicios en materia de capacitación, adiestramiento y productividad de los trabajadores", que mediante el artículo 7 del capítulo segundo, textualmente indica que:

Las Comisiones Mixtas de Capacitación, Adiestramiento y Productividad deberán constituirse en cada empresa que cuente con más de 50 trabajadores, e integrarse de manera bipartita y paritaria, por igual número de representantes de los trabajadores y del patrón.

La integración y el funcionamiento serán determinados y documentados, de común acuerdo, por el patrón y los trabajadores, o en su caso, por el patrón y el sindicato titular del contrato colectivo de trabajo o administrador del Contrato-Ley.

Cuando sea convenido por las partes y las necesidades de la empresa lo ameriten, en razón de su número de establecimientos, de sus características tecnológicas o de la cantidad de trabajadores que ocupe, se podrá constituir más de una comisión mixta, o bien conformar subcomisiones mixtas. (...)

Los representantes del patrón y los trabajadores ante las Comisiones Mixtas de Capacitación, Adiestramiento y Productividad son los responsables de autentificar las constancias de competencias o de habilidades laborales expedidas a los trabajadores que aprueben los cursos de capacitación y adiestramiento, en su caso, cuando aprueben el examen de suficiencia aplicado por la entidad instructora. 
Lo anterior deja claro que la CMCAP deberá conformarse con igual número de representantes de los trabajadores y del patrón, otorgando cierto grado de certidumbre respecto a la resolución que se puede presentar de acuerdo con los servicios que prestaron al patrón durante su contratación por capacitación inicial. Lo anterior impide que el patrón cuente discrecionalmente con la plena facultad de dar por terminada la relación de capacitación inicial argumentando que no logró adquirir las habilidades, conocimientos o experiencia para desempeñar el trabajo.

Es conveniente señalar que el Décimo Tercer Tribunal Colegiado en Materia de Trabajo del Primer Circuito resolvió el 30 de abril de 2015 mediante la Tesis Aislada I.13o.T.128 L (10a.) cuyo rubro es: "CONTRATO DE TRABAJO POR TIEMPO INDETERMINADO SUJETO A CAPACITACIÓN INICIAL. EL PATRÓN NO ESTÁ OBLIGADO A COMUNICAR AL TRABAJADOR LA FECHA DE SU VENCIMIENTO (LEY FEDERAL DEL TRABAJO VIGENTE A PARTIR DEL 10 DE DICIEMBRE DE 2012" lo que se indica a continuación:

Cuando un trabajador suscribe un contrato en términos de los artículos 39-B, 39-C y 39-D de la Ley Federal del Trabajo, vigente a partir del 10. de diciembre de 2012, en el que se hace constar por escrito que está sujeto a capacitación inicial por el periodo de tres meses, o noventa días, desde esa fecha tiene conocimiento, que el contrato cuenta con una vigencia improrrogable, por lo que, concluido el término de capacitación, el patrón no tiene la obligación de comunicar la fecha de su vencimiento pues, desde su suscripción, el actor está enterado de su temporalidad.

En caso de que la Tesis Aislada se convierta en Jurisprudencia, estaríamos en la presencia de una severa dificultad para el trabajador, pues ya no quedaría obligado el patrón a darle aviso de la terminación de la vigencia del contrato, por lo que el trabajador tendría la constante responsabilidad de mantenerse comunicado con el patrón para saber la respuesta respecto a la decisión de continuar o no con el vínculo laboral.

Cabe señalar que a pesar de que la contratación no sea por tiempo indeterminado, el trabajador deberá recibir un salario, prestaciones y seguridad social, lo anterior debido a que se trata de una relación laboral, aunque con una denominación y naturaleza distinta.

Como previamente se ha indicado en la investigación, el trabajador recibirá bajo la mencionada contratación la instrucción necesaria que deba adquirir para desempeñarse en el empleo y/o puesto para el que vaya a ser empleado. Es indispensable señalar que el trabajador debe quedar protegido mediante un contrato laboral establecido de manera escrita para garantizar tanto las condiciones de trabajo como las prestaciones y seguridad social, además de que, ambas partes deben quedar conformes con lo que se pacte en el contrato, a fin de que 
tanto el trabajador como el patrón se sientan conformes, consiguiendo así los mejores resultados del vínculo laboral.

\section{LA CONTRATACIÓN A PRUEBA}

La contratación a prueba para cualquier trabajador, únicamente podrá establecerse cuando la finalidad del patrón sea que el trabajador acredite que cuenta con las habilidades, conocimientos, experiencia, y cualquier otra necesaria para el desempeño del trabajo, es decir, en ésta contratación la persona que prestará sus servicios como trabajador ya cuenta con todos los elementos propios para desempeñar las labores del puesto al que pretende acceder, por lo que sólo demostrará que tiene plena capacidad para realizar las actividades propias de la categoría o puesto en el que se le contratará.

Anteriormente y con base a lo que argumentaba Néstor de Buen Lozano y Octavio Lóyzaga de la Cueva, en la realidad laboral no existía el contrato a prueba, sino la prueba dentro del contrato, que quedó contemplada por “(...) la fracción I del artículo 47 de la ley de 1970", ${ }^{12}$ misma que se analizará más adelante; sin embargo, con la reforma de 2012 que se hizo a la LFT, los legisladores admitieron y aprobaron la modalidad denominada "a prueba". Por lo que en el artículo 39-A textualmente se señaló lo siguiente:

En las relaciones de trabajo por tiempo indeterminado o cuando excedan de ciento ochenta días, podrá establecerse un periodo a prueba, el cual no podrá exceder de treinta días, con el único fin de verificar que el trabajador cumple con los requisitos y conocimientos necesarios para desarrollar el trabajo que se solicita.

El periodo de prueba a que se refiere el párrafo anterior, podrá extenderse hasta ciento ochenta días, sólo cuando se trate de trabajadores para puestos de dirección, gerenciales y demás personas que ejerzan funciones de dirección o administración en la empresa o establecimiento de carácter general o para desempeñar labores técnicas o profesionales especializadas.

Durante el período de prueba el trabajador disfrutará del salario, la garantía de la seguridad social y de las prestaciones de la categoría o puesto que desempeñe. Al término del periodo de prueba, de no acreditar el trabajador que satisface los requisitos y conocimientos necesarios para desarrollar las labores, a juicio del patrón, tomando en cuenta la opinión de la Comisión Mixta de Productividad, Capacitación y Adiestramiento en los términos de esta Ley, así como la naturaleza de la categoría o puesto, se dará por terminada la relación de trabajo, sin responsabilidad para el patrón.

\footnotetext{
12 Octavio Fabián Lóyzaga de la Cueva, "Estabilidad: duración de las relaciones de trabajo", Alegatos 72 (2009): 78.
} 
Como ya se mencionó en párrafos anteriores y de lo señalado en la ley, se desprende que esta modalidad de contratación únicamente se permite cuando la relación laboral sea por tiempo indeterminado, es decir, que se trate de un trabajo de base, o cuando la relación pueda ser superior a 180 días (más de 6 meses). La duración del periodo a prueba varía según la actividad que realizará el trabajador, por lo que puede ser de 30 días ( 1 mes) aunque puede extenderse hasta 180 días (6 meses); no obstante, la extensión del tiempo se aplicará únicamente cuando los servicios que prestará el trabajador requieren de mayor profesionalización o preparación académica por ser más complejos, o también se contempla cuando en el trabajador recaiga la responsabilidad de la fuente de trabajo (puestos de dirección, administración o gerenciales).

De lo anterior evidentemente se desprende que con la reforma a la LFT se atentó en contra del denominado "principio de estabilidad en el empleo", con el cual se planteaba que el trabajador al conseguir vender su fuerza de trabajo a un patrón, podía tener la tranquilidad de que contaría con un empleo seguro, ya que la relación laboral no tendría fecha alguna para la terminación del servicio prestado por el trabajador; sin embargo, actualmente la propia ley ya considera diversos contratos laborales cuya duración puede variar según la naturaleza de la propia relación laboral.

Cualquier trabajador que sea contratado bajo esta denominación tiene todos los derechos que la LFT le otorga como trabajador incluyendo el salario, seguridad social, días de descanso, etcétera, es decir, existen todas las obligaciones y derechos vinculados con la relación laboral. En el contrato no pueden establecerse condiciones ilegales o inferiores a las que dispone la propia ley.

En este sentido, el patrón obtiene la protección jurídica para dar por terminado un vínculo laboral que lo une a un trabajador que no acredita contar con los elementos o conocimientos necesarios para obtener un empleo de carácter indeterminado. El tiempo con el que cuenta el patrón para decidir si contrata al trabajador o no (a facultad discrecional) es de 30 días a 6 meses de acuerdo con lo que establece la ley.

De lo expuesto anteriormente se desprende que, la contratación del trabajador bajo la modalidad de prueba, se utiliza para que se pueda demostrar al trabajador que se tienen los conocimientos y/o habilidades para poder prestar sus servicios en el puesto, categoría o nivel en el que se requiera al trabajador.

La diferencia entre el denominado "contrato a prueba" y la "prueba dentro del contrato" es que el contrato a prueba es una modalidad mediante la cual se puede contratar a 
cualquier trabajador para demostrar que tiene los conocimientos que se requieren para desempeñarse en el puesto que requiera el patrón; sin embargo, es una contratación que se realiza d manera previa a un contrato de tiempo indeterminado o con una duración mayor a los seis meses. La prueba dentro del contrato es aquella en la que se contrata al trabajador sin importar cuál sea la denominación del contrato, pero el patrón cuenta con un lapso de 30 días para supervisar si el trabajador tiene o no los conocimientos para realizar la labor correspondiente, sin omitir que antes del día 31 puede dar por terminada la relación de trabajo sin incurrir en alguna responsabilidad, pero únicamente si se logra demostrar que el trabajador o el sindicato (que propuso al patrón que lo contratara) mintieron respecto a los habilidades, conocimientos o aptitudes del empleado. La fracción I del artículo 47 de la LFT indica que una causa de rescisión imputable de manera directa al trabajador será el hecho de que él o el sindicato que decida proponerlo para ocupar algún puesto laboral, opten por engañar al patrón utilizando certificados falsos, recomendaciones o referencias alteradas con las que se le atribuyan capacidades, aptitudes o facultades que no posee; sin embargo, el patrón cuenta con treinta días para rescindir al trabajador sin ninguna responsabilidad, después de los días señalados, la causal dejará de tener los efectos legales que sirven de protección para el patrón.

Por lo comentado, podemos observar que la estabilidad en el empleo juega un papel importante en las relaciones de trabajo; sin embargo, el papel que ha cobrado actualmente se ha tergiversado, a tal límite que las relaciones de trabajo comienzan a cambiar sin considerar las afectaciones a que se ve expuesto el trabajador.

Cabe mencionar que, en la modalidad a prueba, también posee gran importancia la CMCAP; sin embargo, al igual que en la capacitación inicial, deberá establecerse en las fuentes laborales que tengan contratados a más de 50 trabajadores, en consecuencia, en las micro y pequeñas empresas, que no cumplan con este requisito, se dará la completa libertad al patrón de decidir qué desea hacer con el trabajador: si lo contrata o si decide no hacerlo.

\section{CONCLUSIONES}

La naturaleza de la relación laboral es la que determina el tipo de vínculo jurídico o contrato que podrá establecer el patrón con los trabajadores; no obstante, ambos contratos laborales forzosamente deberán establecerse por escrito, no importando el puesto o categoría que se asignará al trabajador, en el contrato es indispensable estipular todas condiciones de la 
relación laboral y la fecha en que comenzará y terminará el servicio que prestará el trabajador, lo anterior a efecto de que el patrón no tenga conflictos futuros.

La contratación por capacitación inicial se origina cuando el trabajador va a recibir la instrucción para desempeñar el servicio; mientras que la contratación a prueba únicamente se establece para aquellos trabajadores que ya tienen toda la experiencia para desarrollar las actividades del puesto de trabajo, sólo necesitan demostrar los conocimientos que poseen al patrón. Es importante no omitir que para la modalidad con periodo de prueba es un requisito fundamental el que la relación laboral en la que se va a utilizar exceda de ciento ochenta días, pues en caso contrario, no se puede utilizar la modalidad en comento; asimismo, no debemos olvidar que el tiempo que el trabajador permanezca a prueba o por capacitación inicial debe disfrutar del salario, prestaciones y seguridad social.

En ambos contratos (a prueba y/o de capacitación inicial), el trabajador tiene un futuro incierto respecto a la afirmación o negación de un trabajo de carácter indeterminado, ya que ambos quedan establecidos sólo por un tiempo y es facultad discrecional del patrón el decidir si contrata al trabajador o no, según lo que el propio trabajador acredite durante el periodo establecido en la contratación, por lo que se puede afirmar que éste tipo de contrataciones rompen con el principio de estabilidad en el empleo.

Cabe mencionar que ninguno de los contratos en comentario, podrá utilizarse para el detrimento, disminución o menoscabo de los derechos laborales de cualquier persona, ya que los derechos y obligaciones obrero-patronales surgen desde que el momento en que el trabajador comienza a prestar sus servicios, sin importar la forma o denominación que se le asigne a la relación laboral.

El problema al que el contrato a prueba y el contrato de capacitación inicial se enfrentan es que los patrones han realizado un mal manejo de los mencionados, ya que en muchos casos han contratado al trabajador utilizando ambos contratos (un después del otro) aunque la LFT lo prohíba. Lo anterior representa un grave peligro para las relaciones obreropatronales, pues los diversos vínculos laborales comienzan a modificarse sin considerar los perjuicios que se ocasionan a los trabajadores.

La flexibilidad que se otorga para ingresar a las fuentes de trabajo, van adecuando el contenido legal a las necesidades patronales. Es evidente que los abusos que se cometen en contra de los trabajadores, necesitan ser frenados y castigados por las autoridades competentes. No debemos perder de vista que en México ya existía la figura de la prueba dentro del contrato, con lo que podemos afirmar que no se trata de una modalidad novedosa; 
sin embargo, con la reforma de 2012 se intenta ajustar la LFT a la realidad de la contratación de los trabajadores.

Los beneficios de contemplar a la capacitación inicial dentro de las nuevas modalidades de contratación, se relacionan con la protección y el reconocimiento de los derechos laborales que se adjudican al trabajador, ya que un problema evidente en México es que antes de 2012, al momento en que un patrón otorgaba capacitación a una persona que deseaba contratar, no le daba derechos, como: seguridad social, prestaciones e incluso, salario, obteniendo fuerza de trabajo completamente gratuita, lo anterior debido a que se pensaba que por enseñar a las personas la forma de realizar una actividad, era invertir tiempo y esfuerzos innecesarios. De esta manera, como actualmente el patrón se ve obligado a reconocer la capacitación inicial como una relación laboral, evidentemente deberá invertir sus recursos económicos en la enseñanza de los prospectos de trabajadores, evitando que abusen de la figura en comentario.

Cabe reiterar que tanto los patrones como los trabajadores deben tener muy claro que la modalidad a prueba y la de capacitación inicial no se puede aplicar al trabajador de manera simultánea en la misma fuente laboral, tampoco se podrá aplicar a la misma persona, una modalidad de capacitación inicial y posteriormente una modalidad de prueba. El candado mencionado se instauró en la LFT debido a que los abusos patronales son innumerables, además de que los trabajadores generalmente desconocen sus derechos laborales, de lo que podemos afirmar que en caso de que no hubiera sido aprobado en la reforma, se hubiera tenido un grave problema relacionado con la eliminación total de la estabilidad en el empleo.

Cabe reiterar que la duración de la modalidad a prueba y la de capacitación inicial no podrá prorrogarse al tiempo que se haya establecido desde un inicio; asimismo, el trabajador no podrá ser obligado a recibir el mismo tipo de modalidad de contratación en más de una ocasión en la misma fuente de trabajo o con el mismo patrón. Cabe señalar que, si al finalizar la contratación con periodo de prueba o con capacitación inicial se decide mantener el vínculo laboral con el trabajador, el tiempo de la duración de la modalidad deberá formar parte de la antigüedad del trabajador.

Los patrones y trabajadores deben tener presente que el periodo a prueba y el de capacitación inicial no son contratos laborales, sino que son modalidades que se pueden utilizar dentro de la propia relación de trabajo. No debemos perder de vista que no queda a facultad discrecional del patrón decidir si el trabajador debe firmar el contrato laboral prometido, pues, la Comisión Mixta de Productividad, Capacitación y Adiestramiento debe supervisar la opinión que emita respecto a las actividades desempeñadas por el trabajador, a fin de garantizar que la 
clase patronal no abusará de la fuerza de trabajo de miles de personas que únicamente buscan obtener un salario a cambio de los servicios que ofrecen, así, se evita que el trabajador tenga una mayor inestabilidad laboral.

\section{ANEXO}

\section{Contrato individual de trabajo para la modalidad de capacitación inicial}

Que celebran por una parte (nombre completo del patrón o representante legal) a quien en lo sucesivo se le denominará "El Patrón" o "La Patrona", y por la otra (nombre completo del trabajador o de la trabajadora), a quien en lo sucesivo se le denominará como "El Trabajador" o "La Trabajadora", con base en las siguientes declaraciones y cláusulas.

DECLARACIONES

"El Patrón" O “La Patrona" manifiesta bajo protesta de decir verdad:

I. Que mi nombre completo es cual soy mayor de edad, mi nacionalidad es tengo como Clave CURP la siguiente a la presente fecha tengo años por lo sexo y por RFC el mi estado civil es se trata de una empresa entonces deben ir los datos completos de la persona moral así como los del representante legal, aclarando en que calidad están firmando).

II. Que la(s) oficina(s) general(es) de la_fuente laboral tiene(n) el siguiente domicilio

III. Que cuento con patrimonio y elementos propios para cumplir (o responder) respecto a las obligaciones derivadas de la presente relación laboral.

IV. "El Trabajador" o "La Trabajadora" manifiesta bajo protesta de decir verdad:

V. Que mi nombre completo es a la presente fecha tengo años por lo cual soy mayor de edad, mi nacionalidad es , tengo como Clave CURP la siguiente , sexo y por RFC el mi estado civil es

VI. Que tengo por domicilio particular el ubicado en:

VII. Que cuento con los conocimientos y capacidades que se requieren para desarrollar el trabajo que ha originado este contrato, asimismo, aclaro que no padezco de alguna incapacidad que me impida llevarlo a cabo.

VIII. Las partes con fundamento en los artículos 24, 25, 26, 35, 39 B, 39 C, 39 E, 47, 51, 82, $83,84,132,134$ y demás relativos aplicables de la Ley Federal del Trabajo, suscriben la celebración del presente contrato, acordando las siguientes:

\section{Cláusulas}

PRIMERA.- "El Trabajador" (o trabajadora) se obliga a prestar sus servicios personales como (categoría y puesto del trabajador) subordinados a "El Patrón" (o patrona), por tal motivo las actividades que desempeñará consisten en: (describir todas y cada una de las funciones o tareas que el trabajador o trabajadora llevará a cabo, deben detallarse lo mejor posible), acatando, como cualquier otro trabajador, las reglas internas o administrativas de la fuente de trabajo, así como las órdenes que "El Patrón" (o patrona) o cualquier representante de él (o ella) lleguen a hacerle. Cabe mencionar que el presente contrato individual de trabajo es de CAPACITACIÓN INICIAL y su propósito primordial es que "El Trabajador" (o trabajadora) adquiera las habilidades 
y conocimientos necesarios para desempeñar plenamente las actividades propias de (indicar el puesto o la categoría para el que podría ser contratado por tiempo indeterminado el trabajador).

SEGUNDA. - El lugar (o los lugares) donde "El Trabajador" (o trabajadora) debe prestar sus servicios es el ubicado en:

TERCERA. - El presente CONTRATO INDIVIDUAL DE TRABAJO PARA CAPACITACIÓN INICIAL tiene una duración de __ meses, comenzando la capacitación el día __ del mes de__ del año ___ y terminará exactamente el día ___ del mes de___ del año ____. (La duración máxima de este contrato es de tres meses; sin embargo, puede extenderse a seis cuando se trate de trabajadores que podrían ser contratados para desempeñar sus funciones en puestos de dirección, administración, gerenciales, u otros que requieran de conocimientos técnicos o profesionales especializados).

Terminado el periodo de la capacitación inicial, "El Patrón" (o patrona) dará a conocer a "El Trabajador" (o trabajadora) la resolución de si acreditó o no sus habilidades o competencias, tomando en cuenta la opinión de la Comisión Mixta de Capacitación y Adiestramiento, atendiendo, asimismo, a la naturaleza de la categoría o puesto, lo anterior en términos de la propia Ley Federal del Trabajo, en caso de no dar aviso al trabajador, se entenderá que la relación laboral se convertirá en contratación de tiempo indeterminado.

CUARTA. - La duración de la jornada laboral de "El Trabajador" (o trabajadora) será de __ horas semanales, distribuida de las _ horas a las __ horas del día ___ al día de cada semana, atendiendo las normas establecidas en la Ley Federal del Trabajo. Igualmente se establece que por cada _ días de trabajo, "El Trabajador" (o trabajadora) disfrutará de _ día(s) de descanso con goce de salario íntegro, el(los) día(s) de descaso será(n) preferentemente el(los) de cada semana.

En caso de que "El Trabajador" (o trabajadora) labore horas extras, disfrutará de la retribución correspondiente, misma que le será cubierta por "El Patrón" (o patrona) en los términos legales. No se podrán modificar las condiciones de trabajo establecidas en el presente contrato, salvo que sean para beneficiar al trabajador y, únicamente, cuando AMBAS PARTES; es decir, tanto "El Patrón" (o patrona) como "El Trabajador" (o trabajadora) estén de acuerdo con ello.

QUINTA.-_"El Trabajador" (o trabajadora) disfrutará de un salario diario de $\$$ (Cantidad en número) (Cantidad en letra y moneda nacional: PESOS / M.N.) cuya cuantificación (detallar si será semanal o quincenal) asciende a \$(Cantidad en número) (Cantidad en letra y moneda nacional: PESOS / M.N.) y que le será cubierto mediante pago en (indicar si será pago en efectivo o será un depósito bancario, etcétera) los días ___ de cada en (lugar o forma en el que se le entregará al trabajador, ya sea en el domicilio del patrón, en la fuente de trabajo o en una tarjeta bancaria. Para el último caso deberá colocarse la institución bancaria y el número de tarjeta o de cuenta). Debiendo "El Patrón" (o patrona) proporcionar los recibos correspondientes.

El salario mencionado ya incluye la proporción correspondiente al(los) día(s) de descanso; asimismo "El Patrón" (o patrona) deberá hacer los descuentos o deducciones legales correspondientes por concepto de: (Cuota sindical, aportaciones al seguro social que corresponda, ISR, descuento por mandato judicial, créditos, etcétera) al salario de "El Trabajador" (o trabajadora), efectuando las (los) (aportaciones, pagos e inscripciones) ante las instancias o instituciones correspondientes y en los términos legales respectivos.

El salario por ningún motivo podrá reducirse, sin que por ello se entiendan modificadas las condiciones de la capacitación inicial de trabajo señaladas el presente contrato.

SEXTA. - "El Trabajador" (o trabajadora) durante el tiempo que exista la relación laboral, disfrutará de la seguridad social y de las prestaciones de la categoría o puesto que desempeñe, lo anterior se traduce en un periodo vacacional de: y de una prima vacacional conforme 
a: (para ambos casos señalar si es de conformidad con la Ley Federal del Trabajo o con relación al Contrato Colectivo de Trabajo).

También "El Trabajador" (o trabajadora) recibirá un total de \$Cantidad en número (Cantidad en letra y moneda nacional: PESOS / M.N.) por concepto de: (indicar todas y cada una de las cantidades por concepto de aguinaldo, comisiones, incentivos o alguna otra prestación, señalando si es de conformidad con la Ley Federal del Trabajo o con relación al Contrato Colectivo de Trabajo).

SÉPTIMA. - "El Trabajador" (o trabajadora) durante el tiempo que exista la relación laboral, disfrutará del pago por concepto de Participación de Utilidades.

OCTAVA. - "El Trabajador" (o trabajadora) tendrá el derecho a ser ascendido cuando demuestre haber adquirido conocimientos o aptitudes para desempeñarse en un puesto o categoría mayor en comparación con la que tenía al principio de la relación laboral.

NOVENA. - "El Patrón" (o patrona) queda obligado con "El Trabajador" (o trabajadora) a proporcionarle los instrumentos, materiales, herramientas, maquinaria, medios, etcétera, indispensables para llevar a cabo su trabajo.

DECIMA.-. "El Patrón" (o patrona) queda obligado con "El Trabajador" (o trabajadora) a proporcionarle la capacitación y el adiestramiento necesarios para mejorar los servicios laborales que se proporcionan.

DECIMA PRIMERA. - "El Patrón" (o patrona) deberá ofrecer a "El Trabajador" (o trabajadora) condiciones apropiadas en relación a la Seguridad, Higiene y Medio ambiente en las instalaciones de la fuente de trabajo. La importancia de todo lo anterior radica en prevenir los riesgos de trabajo adoptando las medidas necesarias para ello.

DECIMA SEGUNDA.-. Tanto "El Patrón" (o patrona) como "El Trabajador" (o trabajadora) se obligan a respetar las disposiciones contenidas en el Contrato Colectivo de Trabajo y/o en el Reglamento Interior de Trabajo (en caso de que existan, claro).

DECIMA TERCERA. - Cualquier disposición no contenida en el presente contrato, será respetada conforme a las disposiciones previstas en la Ley Federal del Trabajo o el Contrato Colectivo de Trabajo, así como por el Reglamento Interior de Trabajo que prevalecen en la fuente de trabajo.

Leído que fue el presente contrato por las partes que en él intervienen, lo ratifican respecto a todo su contenido, asimismo se reconoce que todo lo que en este contrato se tiene previsto, se apega a las disposiciones de la Ley Federal del Trabajo y al Contrato Colectivo de Trabajo o al Reglamento Interior de Trabajo que prevalecen en la fuente de laboral, en caso contrario, se tendrá que reconocer como un contrato de trabajo invalido y se procederá conforme a lo señalado en la Ley Federal del Trabajo.

En México a de _ de

"El Trabajador" (o trabajadora)

"El Patrón" (o patrona)

\section{Nombre}

Nombre

TESTIGOS

Nombre del testigo

Nombre del testigo 


\section{BIBLIOGRAFÍA}

BARAJAS MONTES DE OCA, Santiago. Los contratos especiales de trabajo (México: Universidad Nacional Autónoma de México, 1992).

BERMÚDEZ CISNEROS, Miguel. Derecho del trabajo (México: Oxford, 2012).

CALVA, José Luis. El modelo neoliberal mexicano: costos, vulnerabilidad, alternativas (México, Juan Pablos Editor, 1995).

CERVANTES NIETO, Héctor. Consejos prácticos sobre el contrato individual de trabajo. Lineamientos básicos para la prevención de problemas en las relaciones laborales (México: Ediciones fiscales ISEF, 2005).

Constitución Política de los Estados Unidos Mexicanos. Vigente. Acceso el 15 de diciembre de 2016. http://www.diputados.gob.mx/LeyesBiblio/pdf/1_240217.pdf.

DE BUEN L., Néstor. Derecho del trabajo (México: Editorial Porrúa, 2013).

DE LA CUEVA, Mario. El nuevo derecho mexicano del trabajo, Tomo I, (México: Porrúa, 2011).

Diario Oficial de la Federación. Decreto por el que se reforman, adicionan y derogan diversas disposiciones de la LFT. Acceso el 15 de diciembre de 2016. http://dof.gob.mx/nota_detalle.php?codigo=5280815\&fecha=30/11/2012.

FÉLIX TAPIA, Ricardo de la Luz. Relaciones Laborales. Legislación, Formularios y Jurisprudencia (México: Flores Editor y distribuidor, 2008).

GARRIDO RAMÓN, Alena. Derecho individual del trabajo (México: Oxford, 2015).

HERNÁNDEZ HERRERA, Juan y Carlos Antonio Juárez Suárez, Derecho laboral y la administración de recursos humanos (México: Grupo editorial patria, 2015).

KURCZYN VILLALOBOS, Patricia. Las nuevas relaciones de trabajo (México: Porrúa - UNAM, 1999).

Ley Federal del Trabajo. Vigente. Acceso el 26 de diciembre de 2016. http://www.diputados.gob.mx/LeyesBiblio/pdf/125_120615.pdf.

LÓYZAGA DE LA CUEVA, Octavio. El derecho del trabajo. Un análisis crítico (México: Universidad Autónoma Metropolitana, 2015).

"Estabilidad: duración de las relaciones de trabajo", Alegatos 72, Universidad Autónoma Metropolitana Unidad Azcapotzalco, División de Ciencias Sociales y Humanidades (2009): 67-81.

PALAVICINI, Félix Fulgencio. Historia de la Constitución de 1917, Tomo I (México: Gobierno del estado de Querétaro, Instituto Nacional de Estudios Históricos de la Revolución Mexicana de la Secretaría de Gobernación, 1987). 
REYNOSO CASTILLO, Carlos y Alfredo Sánchez-Castañeda. La nueva legislación laboral mexicana (México: Universidad Nacional Autónoma de México, Instituto de Investigaciones Jurídicas, 2013).

SÁNCHEZ-CASTAÑEDA, Alfredo. Las transformaciones del derecho del trabajo (México: Universidad Nacional Autónoma de México, 2006).

SANTOS AZUELA, Héctor y Verónica Santos Méndez. Fundamentos y reforma del derecho del trabajo (México: Porrúa, 2014).

Secretaría del Trabajo y Previsión Social. Acceso el 21 de agosto de 2016. http://www.stps.gob.mx.

Suprema Corte de Justicia de la Nación. Acceso el 28 de octubre de 2016. https://www.scjn.gob.mx.

Trabalho enviado em 16 de novembro de 2017.

Aceito em 05 de fevereiro de 2018. 